\title{
Characterization of Glasses in One Type of Alumina Rich Fly Ash by Chemical Digestion Methods: Implications for Alumina Extraction
}

\author{
Lijun Zhao, ${ }^{1}$ Hanshuang Xiao, ${ }^{2}$ Baodong Wang, ${ }^{1}$ and Qi Sun ${ }^{1}$ \\ ${ }^{1}$ Coal Resource Utilization COE, National Institute of Clean-and-Low-Carbon Energy, Shenhua NICE, \\ Xiaotangshan Future Science \& Technology City, P.O. Box 001, Changping District, Beijing 102211, China \\ ${ }^{2}$ Department of Chemistry, Tongji University, No. 1239 Siping Road, Shanghai 200092, China \\ Correspondence should be addressed to Lijun Zhao; zhaolijun@nicenergy.com
}

Received 26 November 2015; Revised 28 December 2015; Accepted 30 December 2015

Academic Editor: Hossein Kazemian

Copyright (C) 2016 Lijun Zhao et al. This is an open access article distributed under the Creative Commons Attribution License, which permits unrestricted use, distribution, and reproduction in any medium, provided the original work is properly cited.

\begin{abstract}
In recent years, one type of alumina rich fly ash (ARFA) with about $50 \mathrm{wt} \%$ of alumina has been extensively investigated for alumina extraction in China. Due to the silica in ARFA, alumina extraction would have to generate a huge amount of solid waste. There is a growing interest in the glasses in ARFA, because they are composed mainly of silica and could be removed prior to alumina extraction. In this work, the glasses in ARFA have been investigated by chemical methods, that is, acid and base digestions. The chemical compositions have been measured by XRF for ARFA from the digestion processes. The $\mathrm{K}_{2} \mathrm{O}$ standard, XRD, and FTIR spectroscopies were successfully used to define the digestions processes, and size analysis and SEM-EDX provided rich information on particle transformations. As a result, acid and base digestion methods were found to produce very similar results for the glasses in ARFA. The $\mathrm{K}_{2} \mathrm{O}$ standard was attributed to the formation of glasses by illites, and $\mathrm{TiO}_{2}$ and $\mathrm{Fe}_{2} \mathrm{O}_{3}$ were proposed to originate from ilmenite in alumina rich coals (ARC). Some implications of the results were also discussed for the alumina extraction from ARFA.
\end{abstract}

\section{Introduction}

China's alumina industry relies heavily on foreign bauxite, which accounts for more than $60 \%$ of its total consumption, according to China Industry Security Guide. It has been found that the coal deposits in the Midwest of Inner Mongolia Autonomous Region and North Shanxi Province of China are rich in alumina $[1,2]$. After burning alumina rich coal (ARC) for power generation, a huge amount of alumina rich fly ash (ARFA) has been produced, and routinely buried deep in ground or piled up in open fields, causing serious environment problems [1-4]. The ARFA occurs with about $50 \mathrm{wt} \%$ of alumina favorable for alumina extraction, as well as about $40 \mathrm{wt} \%$ of silica. Besides, about $10-30$ billion tons of ARFA would be produced in these regions.

Recently, a comprehensive review of alumina extraction from fly ash has been published with a focus on China [1]. For the promising sintering methods, a large amount of lime has to be added to react with silica for the formation of solid wastes like $2 \mathrm{CaO} \cdot \mathrm{SiO}_{2}$, so that alumina could be extracted. As a result, even more waste is produced than the alumina extracted. For the ARFA, silica occurs mainly in glassy state or as part of mullite [2-4]. Hot dilute caustic solutions readily dissolve silica in glassy state, and predesilication should be preferably performed for ARFA prior to alumina extraction. Predesilication reduces silica in ARFA, lime addition would accordingly be decreased, and so does the waste production [1-4].

Glasses in fly ash have attracted much attention for a long time. In the early days [5], researchers became interested in the glasses because they affect the stability of fly ash added in cement. The natural weathering of fly ash proceeds with the dissolution of glasses [6], and the glasses provide predominant component of dissolved iron in the open ocean [7]. A variety of zeolites have been synthesized by dissolving the glasses for applications like ion exchange, gas adsorption, 
and water adsorption [8-11]. More recently, the dissolved glasses have been used to produce ultra-clear glass [3], white carbon black and active calcium silicate [12].

In this work, the concern is the amount and nature of glasses in ARFA, because it could set the predesilication limit for alumina extraction from ARFA. Generally, two groups of methods have been developed for the study of glasses in fly ashes [5], that is, spectroscopic methods like XRD and chemical methods like acid and base digestions. Despite the great progress in quantifying the glasses in fly ashes [13-16], the XRD has been generally regarded as a semiquantitative tool, due to inherent variability of a number of crystal frameworks, sample preparation, grainsize effects, preferred orientation, and absorption of X-rays by other components. Other spectroscopic techniques like NMR, FTIR, and Raman have been known to mainly yield qualitative information on the chemical compositions of the glasses in fly ash $[2,5]$. The chemical methods highlight acid (HF) and base $(\mathrm{NaOH})$ digestions of glasses in fly ashes. Dilute HF solutions have been known to rapidly digest the glasses in fly ashes, and the process could be readily traced [17-19]. For $\mathrm{NaOH}$ solution digestion of glasses in fly ashes, three steps should be involved, that is, step Base Dissolution I, step Acid Dissolution ( $\mathrm{HCl}$ ), and step Base Dissolution II [2]. It seems that the glasses in ARFA can be effectively characterized by utilizing chemical methods corroborated by spectroscopic techniques.

\section{Experimental}

\subsection{Procedures for Acid and Base Digestions of ARFA}

2.1.1. Acid Digestion of ARFA. The ARFA samples have been taken from one of Shenhua Group's power plants. A weighted ARFA sample of $10.0 \mathrm{~g}$ was added to a $1.0 \mathrm{wt} \%$ HF solution of $1000 \mathrm{~mL}$ at the ambient temperatures of $20 \pm 1^{\circ} \mathrm{C}$, and the solution was stirred for a predetermined interval. Then, the solution was filtered and washed to obtain the sample of acid digestion ARFA. Since $1.0 \mathrm{wt} \%$ HF solution has been known to easily digest the glasses in fly ashes [17-19], the first interval was set at $15 \mathrm{~min}$, and other intervals were $1 \mathrm{hr}, 2 \mathrm{hr}, 4 \mathrm{hr}, 8 \mathrm{hr}$, $16 \mathrm{hr}$, and $32 \mathrm{hr}$. All acid digestion ARFA samples were dried at $120^{\circ} \mathrm{C}$ overnight for analysis.

2.1.2. Base Digestion of ARFA. This method involves three steps, and it is claimed that the glasses in ARFA would be totally removed through the procedures [2]. Step Base Dissolution I: a weighted ARFA sample of $40.0 \mathrm{~g}$ was added in a $30.0 \mathrm{wt} \%$ base solution prepared by dissolving $20.0 \mathrm{~g}$ $\mathrm{NaOH}$ and was allowed to react at $95^{\circ} \mathrm{C}$ for $4 \mathrm{hr}$ prior to filtering and washing. The cake was dried at $120^{\circ} \mathrm{C}$ overnight for analysis. Step Acid Dissolution: the cake prepared in the step Base Dissolution I was transferred into a $15.0 \mathrm{wt} \% \mathrm{HCl}$ solution of $80 \mathrm{~mL}$. The slurry was allowed to react at $80^{\circ} \mathrm{C}$ for $1 \mathrm{hr}$ prior to filtering and washing, and the cake was dried at $120^{\circ} \mathrm{C}$ overnight for analysis. Step Base Dissolution II: the cake prepared by going through the steps Base Dissolution I and Acid Dissolution was further treated precisely as Step Base Dissolution I.
2.2. Characterization and Measurement of ARFA Samples. XRF (ZSX Primus II), XRD (RINT 2000), and FTIR (Nicolet Nexus) measurements were applied for the dried ARFA from acid and base digestion processes. Particle transformations of ARFA in digestion processes were investigated by SEM-EDX (S4800-EMAX) and size analysis (Mastersizer 3000).

\section{Results and Discussion}

3.1. Chemical Compositions and Weights of ARFA in Acid and Base Digestion Processes. The weight percentage changes of ARFA are shown in Figure 1 for acid and base digestion processes. In Figure 1(a) for acid digestion process, the weight of ARFA decreases rapidly in the beginning and even within $15 \mathrm{~min}$ over $20 \mathrm{wt} \%$ is lost into the HF solution. The rate of weight loss then slows down and decreases linearly till the interval of $4 \mathrm{hr}$ with a loss of $38.1 \mathrm{wt} \%$. After that, the rate of weight loss becomes increasingly slower, and $55.9 \mathrm{wt} \%$ of ARFA is lost in the interval of $32 \mathrm{hr}$. In Figure 1(b) for base digestion process (0-4 hr: step Base Dissolution I, 4-5 hr: step Acid Dissolution, and 5-9 hr: step Base Dissolution I), the weight of ARFA decreases faster in step Acid Dissolution, and $40.2 \mathrm{wt} \%$ of ARFA is finally lost after step Base Dissolution II.

Chemical compositions of acid and base digestion ARFA measured by XRF are given in Figure 2, and only major components in the form of stable oxides with contents higher than $1 \mathrm{wt} \%$ are presented, such as $\mathrm{SiO}_{2}, \mathrm{Al}_{2} \mathrm{O}_{3}, \mathrm{CaO}, \mathrm{TiO}_{2}$, and $\mathrm{Fe}_{2} \mathrm{O}_{3}$. In addition, $\mathrm{K}_{2} \mathrm{O}$ is also given in Figure 2, because it may serve as an indicator for glass digestion. Figure 2 is intended only to provide an illustration of chemical compositions of ARFA after digestions, and the patterns should not be quantitatively related to the trends of component dissolution.

3.2. Identification of Glasses in ARFA in Acid Band Base Digestion Processes. It has been generally agreed that chemical digestions can dissolve glasses as well as other phases in fly ashes, depending on the conditions $[2,19]$. In this section, $\mathrm{K}_{2} \mathrm{O}$ standard, XRD, FTIR, SEM, and size analysis have been used to characterize ARFA in acid and base digestion processes, and based upon the results the glasses have been clearly identified from other components in ARFA.

3.2.1. $\mathrm{K}_{2} \mathrm{O}$ Standard. With the exhaustive experiments, it has been found that "the completion of removal of the potassium could serve as a maker for completion of dissolution of the glass phase in the fly ash" [19]. According to the weight percentages of acid digestion ARFA in Figure 1(a) and the weight percentages of $\mathrm{K}_{2} \mathrm{O}$ in acid digestion ARFA in Figure 2(a), the absolute weights of $\mathrm{K}_{2} \mathrm{O}$ in acid digestion ARFA can be conveniently calculated. In Figure $3, \mathrm{~K}_{2} \mathrm{O}$ in acid digestion ARFA has been given in weight percentage of total $\mathrm{K}_{2} \mathrm{O}$ in raw ARFA as a function of acid digestion time, and there is still $5 \mathrm{wt} \% \mathrm{~K}_{2} \mathrm{O}$ retained even in the interval of $32 \mathrm{hr}$. The remaining $\mathrm{K}_{2} \mathrm{O}$ probably occurs in some forms that cannot be easily attacked by acid, for example, contained or buried as impurities in mullite and corundum crystals. Therefore, once $\mathrm{K}_{2} \mathrm{O}$ becomes stable in ARFA samples in given intervals, the glasses could be regarded as completely dissolved or digested. 


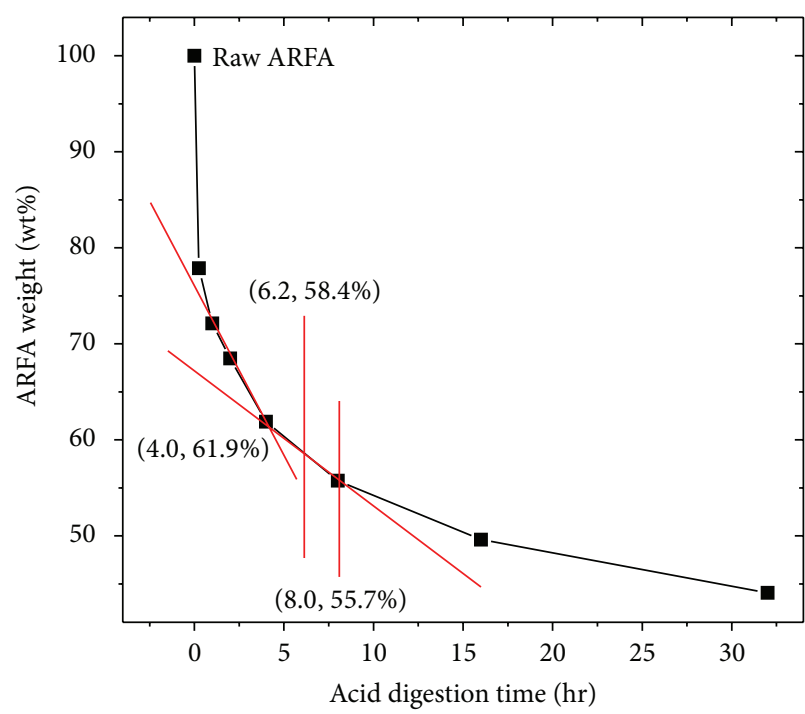

ARFA weight in acid digestion process

(a)

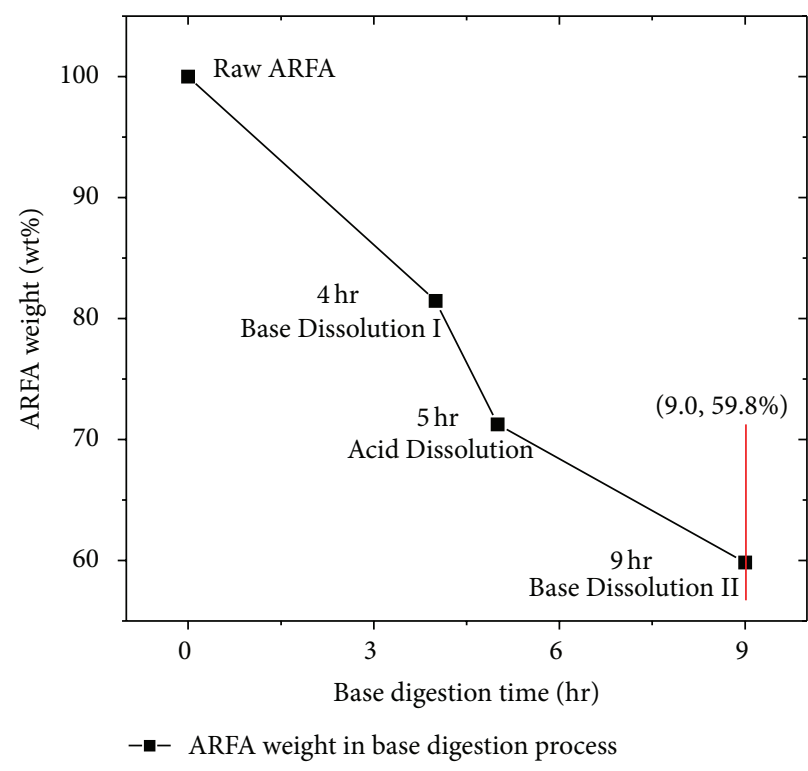

(b)

FIGURE 1: Weight changes of ARFA in acid (a) and base (b) digestion processes.

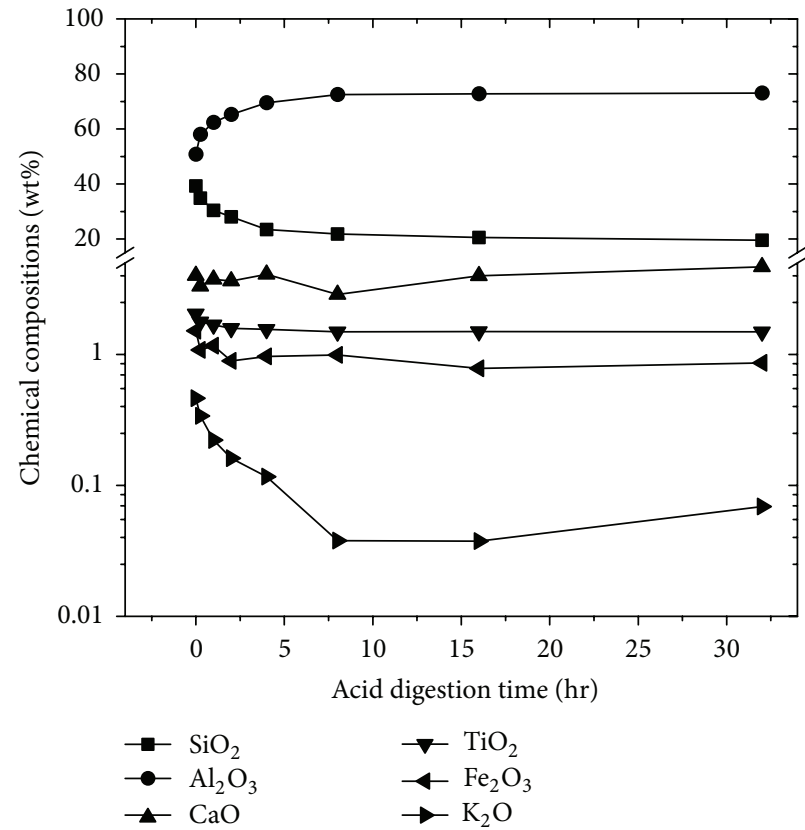

(a)

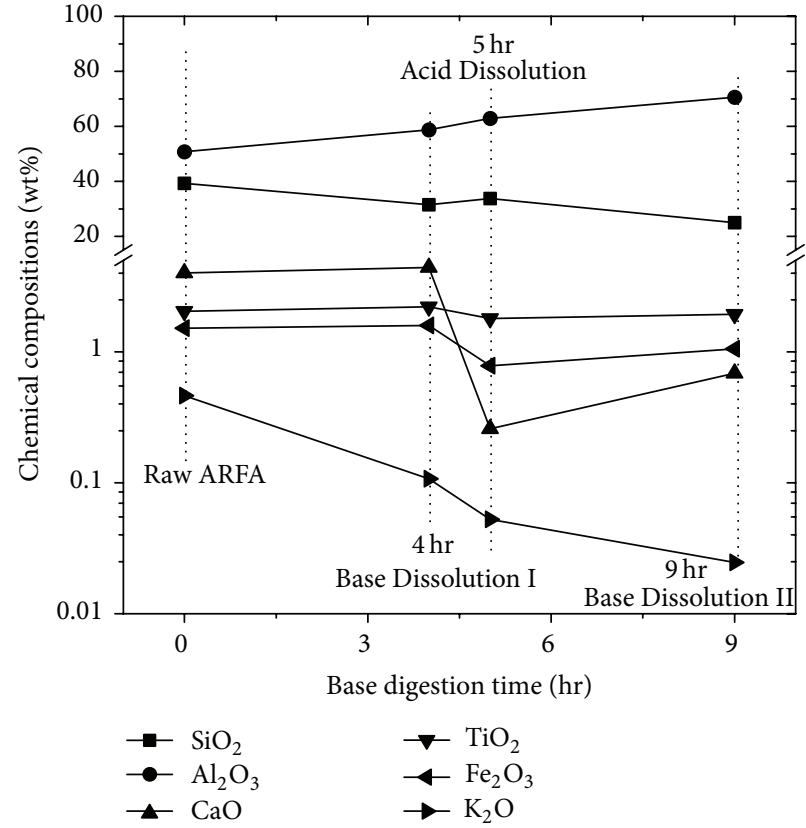

(b)

FIGURE 2: Chemical composition changes of ARFA by XRF in acid (a) and base (b) digestion processes.

In Figure 3, it is apparent that $\mathrm{K}_{2} \mathrm{O}$ in acid digestion process becomes stable at the interval of $8 \mathrm{hr}$. However, there is also the possibility of achieving a stable $\mathrm{K}_{2} \mathrm{O}$ at an earlier time than the interval of $8 \mathrm{hr}$. Such time could be estimated by drawing a line through $\mathrm{K}_{2} \mathrm{O}$ masses at intervals $2 \mathrm{hr}$ and $4 \mathrm{hr}$ to cross the line for $\mathrm{K}_{2} \mathrm{O}$ of $5 \mathrm{wt} \%$, and it is determined to be $6.2 \mathrm{hr}$. Therefore, the complete removal of $\mathrm{K}_{2} \mathrm{O}$ may occur at $6.2-8 \mathrm{hr}$ in acid digestion process. According to Figure 1(a), $41.6 \mathrm{wt} \%$ and $44.3 \mathrm{wt} \%$ of ARFA were lost at $6.2 \mathrm{hr}$ and $8 \mathrm{hr}$ in acid digestion process, which should be set as the lower and upper limits of glasses in ARFA. If the average is taken, the completion of glass digestion may occur at $7.1 \mathrm{hr}$ with a loss of $42.9 \mathrm{wt} \%$. By contrast, according to Figure 1(b) for base digestion process, about $40.2 \mathrm{wt} \%$ of ARFA was lost in the base digestion time of $9 \mathrm{hr}$ after step Base Dissolution II, which has been taken as the glass content [2]. Therefore, the glass content measured by base digestion process is about $2.7 \mathrm{wt} \%$ lower than acid digestion process. 


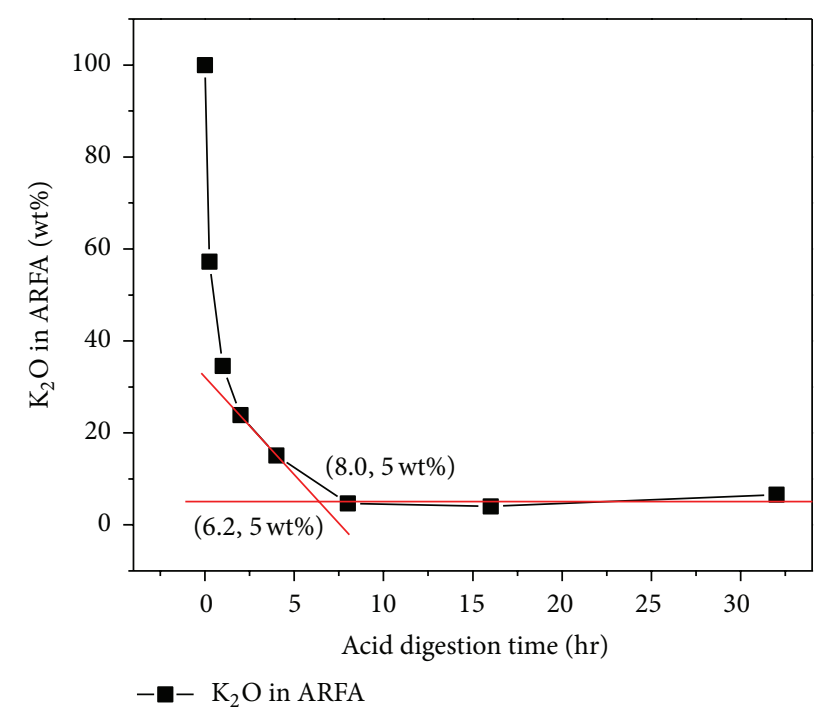

FIGURE 3: $\mathrm{K}_{2} \mathrm{O}$ in ARFA from acid digestion process.

In the study by quantitative XRD spectroscopy of 75 European fly ashes, a wide range of glass contents from $45 \mathrm{wt} \%$ to $90 \mathrm{wt} \%$ have been calculated [16], and low alkali oxides were found not to support high glass contents. The alkali oxides are mainly $\mathrm{K}_{2} \mathrm{O}$ of $0.46 \mathrm{wt} \%$ in ARFA, and therefore, even lower glass content of 40.2-42.9 wt $\%$ has been reported in this work by acid and base digestions. It should be noted that the glass contents in ARFA were among the lowest according to the literature survey $[5,13-16]$.

3.2.2. XRD Spectroscopy. In Figure 4(a), the XRD spectra in the $2 \theta$ range of $10-60^{\circ}$ are given for acid digestion ARFA, as well as raw ARFA. In raw ARFA, major crystal phases are mullite and corundum. The weak peak with $2 \theta$ at $29.3^{\circ}$ may be ascribed to ferrite spinel, which has been dissolved even in $15 \mathrm{~min}$ [19-21]. The broad band in the $2 \theta$ range of $15-30^{\circ}$ has been previously linked with the glasses in fly ashes $[2,5]$. Three little peaks above the broad band could originate from the crystalline silica forms, such as tridymite and quartz [5], which have also been dissolved in $15 \mathrm{~min}$. In the XRD spectra of $32 \mathrm{hr}$, a new peak with $2 \theta$ at $29.0^{\circ}$ might be attributed to $\mathrm{CaF}_{2}$ crystal formed in extended period of time [22]. In Figure 4(b), the broad band is enlarged to display the glasses digestion of ARFA. The broad band of glasses is disappearing from $15 \mathrm{~min}$ to $8 \mathrm{hr}$, after which it becomes almost flat till $32 \mathrm{hr}$, which is in good agreement with the $\mathrm{K}_{2} \mathrm{O}$ standard.

In Figures 5(a) and 5(b), the XRD spectra in the same $2 \theta$ ranges are given for base digestion of ARFA, as well as raw ARFA. The peak for ferrite spinel remains, though greatly weakened, after step Base Dissolution I and disappears totally when step Acid Dissolution is applied. It seems that ferrite spinel is more resistant to base than acid digestion. The broad band of glasses becomes increasingly flat with the progress of base digestion process, and the small peaks for crystalline silica disappear after step Base Dissolution I. A new peak with $2 \theta$ at $24.4^{\circ}$ appears after step Base Dissolution I, disappears when step Acid Dissolution is applied, and reappears with a

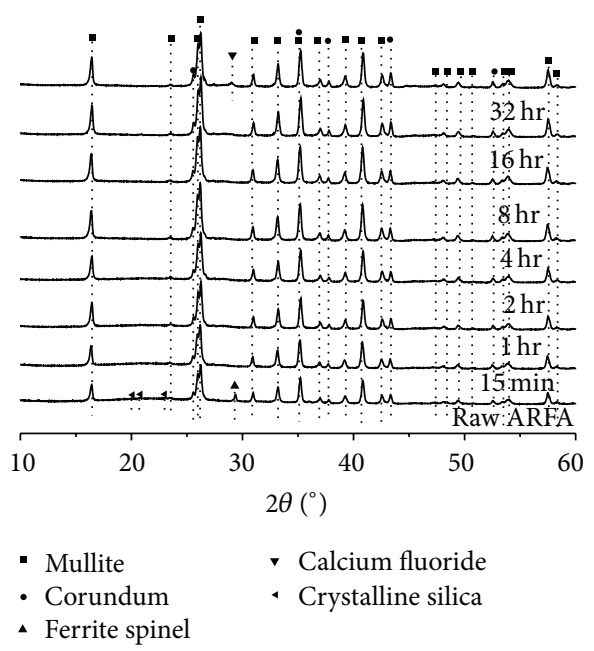

(a)

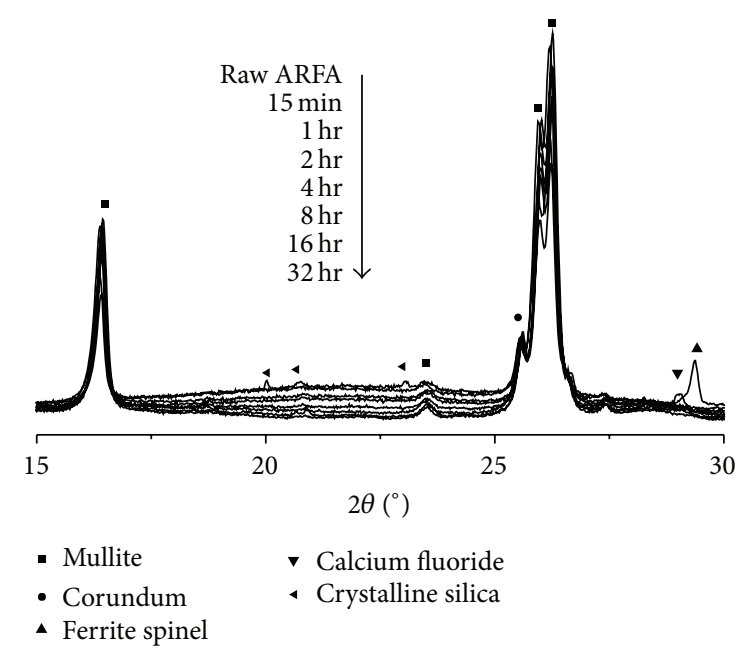

(b)

FIGURE 4: The XRD spectra of ARFA from acid digestion process, (a) in the $2 \theta$ range of $10-60^{\circ}$ and (b) in the enlarged $2 \theta$ range of 15$30^{\circ}$. Note that the spectra in (a) have been offset for clarity and the spectra in (b) are given without treatments.

slightly different $2 \theta$ at $24.6^{\circ}$ after step Base Dissolution II. The peak has been previously attributed to hydroxysodalite [10]. Hydroxysodalite formation in step Base Dissolution I blocked glass digestion, and step Acid Dissolution was applied to destroy it, so that glasses could be completely digested by step Base Dissolution II [2]. But from the XRD spectra for step Base Dissolution II, hydroxysodalite still occurs to cover the ARFA. This could explain why acid digests more glasses (2.7 wt\%) than base.

3.2.3. FTIR Spectroscopy. In Figure 6(a) for the FTIR spectra of acid digestion ARFA and raw ARFA, the three peaks at $563 \mathrm{~cm}^{-1}, 740 \mathrm{~cm}^{-1}$, and $875 \mathrm{~cm}^{-1}$ seem stationary and get increasingly shaped with the progress of acid digestion. Therefore, the three peaks should represent the acid-resistant components of ARFA and are attributed mainly to mullite 


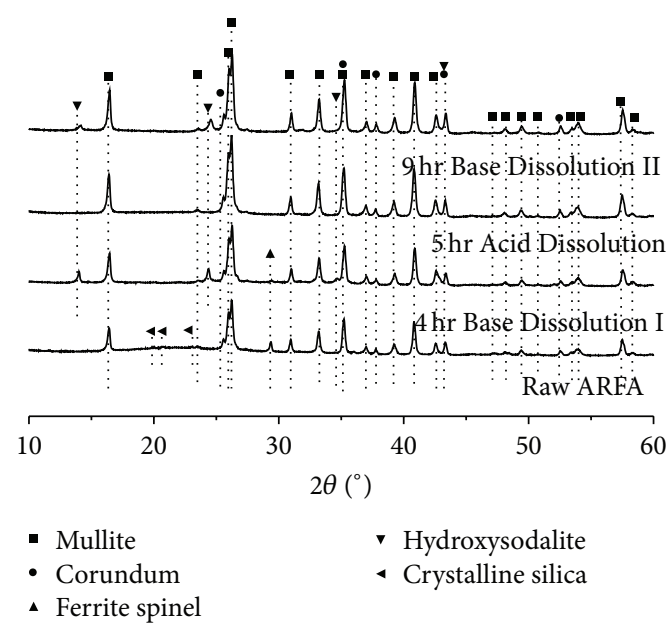

(a)

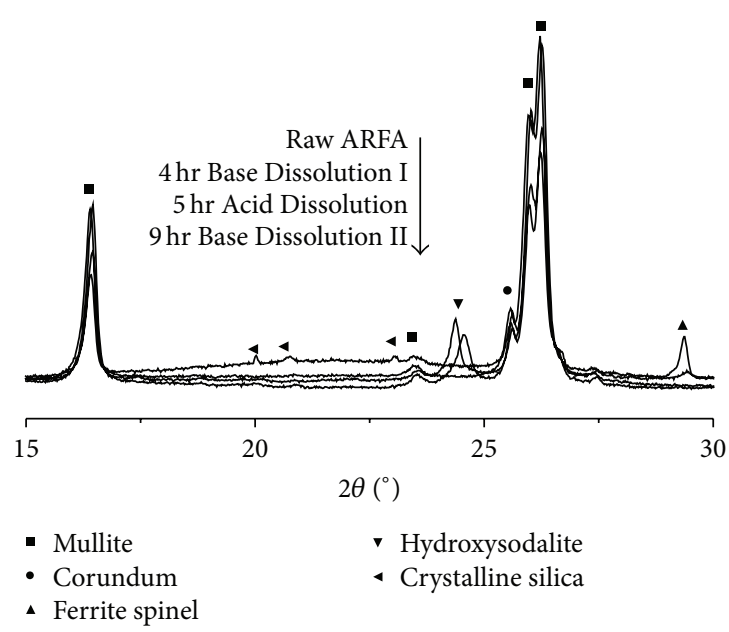

(b)

FIGURE 5: The XRD spectra of ARFA from base digestion process, (a) in the $2 \theta$ range of $10-60^{\circ}$ and (b) in the enlarged $2 \theta$ range of $15-30^{\circ}$. Note that the spectra in (a) have been offset for clarity and the spectra in (b) are given without treatments.

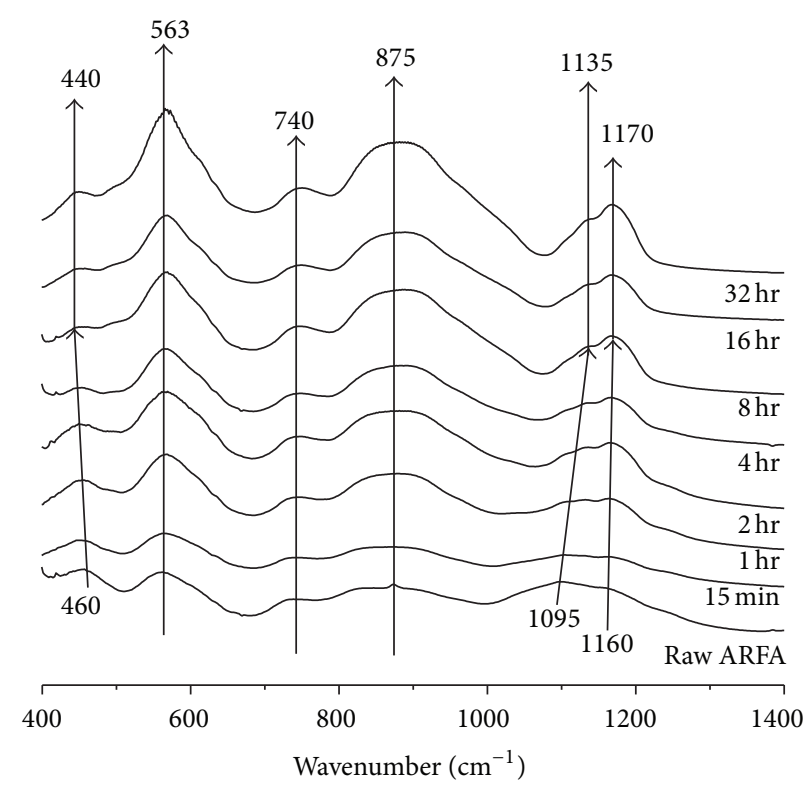

(a)

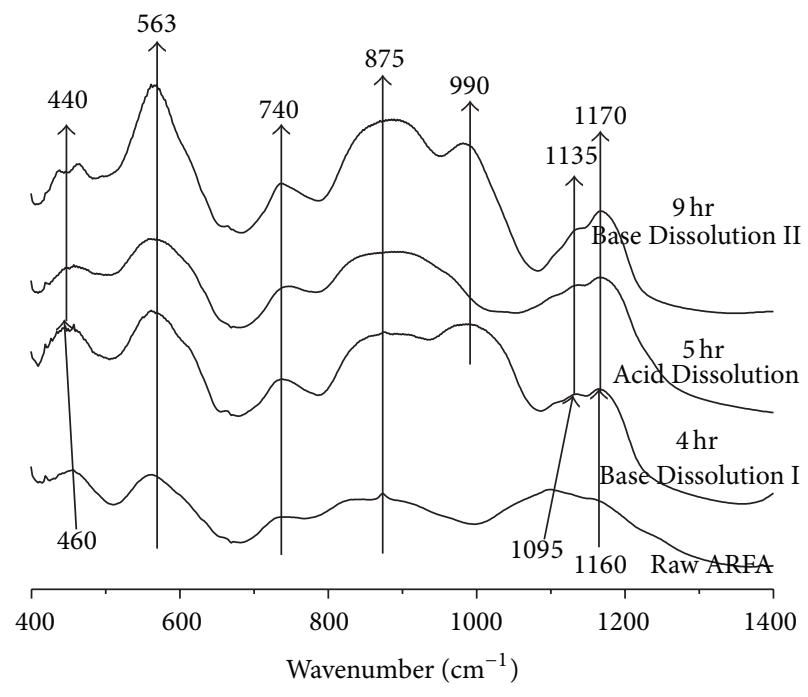

(b)

FIgURE 6: The FTIR spectra of ARFA from acid (a) and base (b) digestion processes. Note that the spectra in (a) and (b) have been offset for clarity.

[23]. By contrast, as acid digestion proceeds from $0 \mathrm{hr}$ to $8 \mathrm{hr}$, the peak at $460 \mathrm{~cm}^{-1}$ moves to $440 \mathrm{~cm}^{-1}$, and the peaks at $1095 \mathrm{~cm}^{-1}$ and $1160 \mathrm{~cm}^{-1}$ move to $1135 \mathrm{~cm}^{-1}$ and $1170 \mathrm{~cm}^{-1}$, respectively. The band at around $450 \mathrm{~cm}^{-1}$ has been assigned to the O-Si-O bending vibration and will red-shift as the matrix becomes increasingly polymerized (3D, sheets). The bands at around $1150 \mathrm{~cm}^{-1}$ have been attributed to $\mathrm{Si}-\mathrm{O}$ stretching vibration and will blue-shift as the matrix gets increasingly polymerized (3D, sheets) $[5,19,23]$. The glasses in fly ashes are known to represent a depolymerized matrix (chain, sheets). Therefore, the red-shift from $460 \mathrm{~cm}^{-1}$ to $440 \mathrm{~cm}^{-1}$ and the blue-shifts from $1095 \mathrm{~cm}^{-1}$ to $1135 \mathrm{~cm}^{-1}$ and from $1160 \mathrm{~cm}^{-1}$ to $1170 \mathrm{~cm}^{-1}$ should correspond to glasses digestion of ARFA. As acid digestion proceeds further to $16 \mathrm{hr}$ and $32 \mathrm{hr}$, all the peaks present no changes in their positions and can be roughly assigned to mullite [23].

In Figure 6(b) for the FTIR spectra of base digestion process, similar observations can also be made. With the progress of base digestion, the three peaks at $563 \mathrm{~cm}^{-1}$, $740 \mathrm{~cm}^{-1}$, and $875 \mathrm{~cm}^{-1}$ do not change very much and should correspond to the base-resistant components comprised mainly of mullite. Even after step Base Dissolution I, the peak at $460 \mathrm{~cm}^{-1}$ has moved to $440 \mathrm{~cm}^{-1}$ and the peaks at $1095 \mathrm{~cm}^{-1}$ and $1160 \mathrm{~cm}^{-1}$ have moved to $1135 \mathrm{~cm}^{-1}$ and 


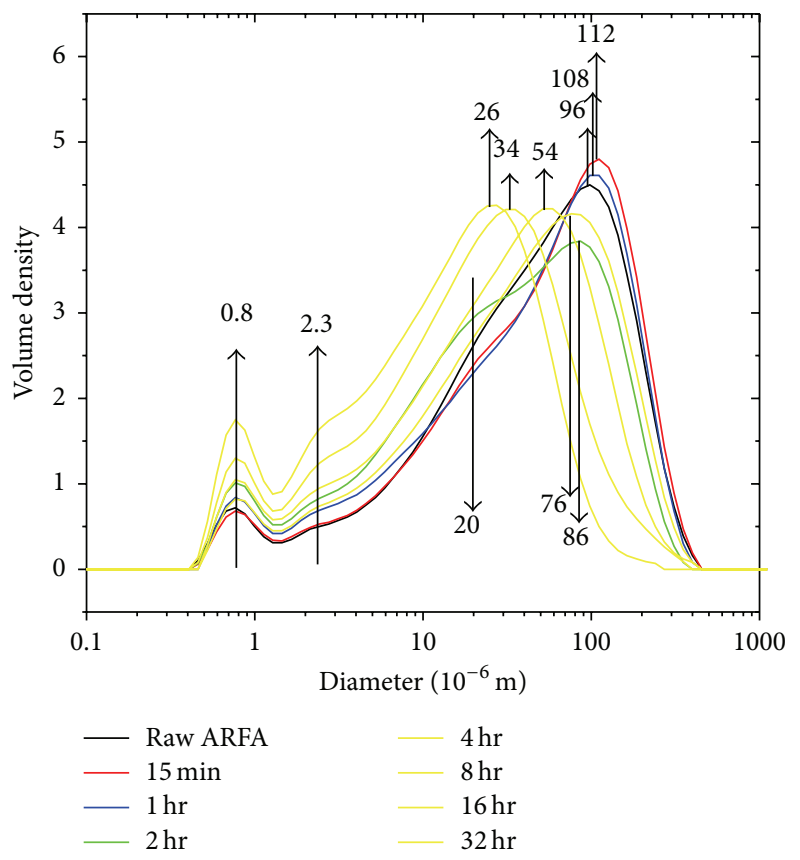

(a)

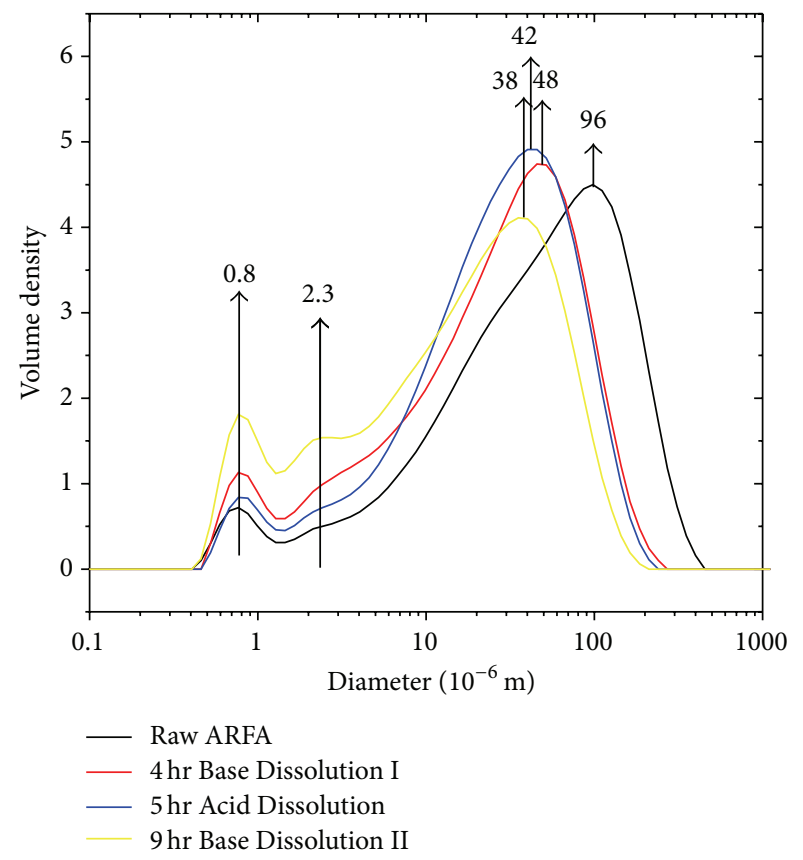

(b)

FIGURE 7: Particle transformations in acid (a) and base (b) digestion processes.

$1170 \mathrm{~cm}^{-1}$, respectively. This means the glasses in ARFA may have been largely digested, but there is a new peak appearing at around $990 \mathrm{~cm}^{-1}$, which can be assigned to hydroxysodalite according to previous studies of zeolite synthesis from coal ash [24]. Hydroxysodalite forms by dissolved silica and alumina in step Base Dissolution I and can be destroyed by acid. In step Acid Dissolution, hydroxysodalite was totally removed, as substantiated by the disappearance of the peak at around $990 \mathrm{~cm}^{-1}$. In step Base Dissolution II to digest the glasses in ARFA, the peak assigned to hydroxysodalite appears once again, though greatly weakened. Therefore, the glasses obtained by base digestion would be underestimated.

3.2.4. Size Analysis. Though the morphologies of fly ashes have been extensively investigated by SEM and TEM, revealing interesting features like cenosphere and plerosphere [5, $12,25]$, the information on particle transformations has rarely been reported. In this work, to define acid and base digestion processes, the size distributions of ARFA samples have been measured, and the results are given in Figure 7.

In Figure 7(a), the size distributions for acid digestion ARFA and raw ARFA have been plotted for comparison. The main peak for raw ARFA occurs at $96 \mu \mathrm{m}$, and after $15 \mathrm{~min}$ and $1 \mathrm{hr}$ in acid digestion process, it moves to $108 \mu \mathrm{m}$ and $112 \mu \mathrm{m}$. This means medium size particles tend to be digested in the beginning. When acid digestion proceeds to $2 \mathrm{hr}$, the main peak breaks into two parts, one at $86 \mu \mathrm{m}$ and the other at $20 \mu \mathrm{m}$, and many large particles could have collapsed in this moment. When acid digestion proceeds further to $4 \mathrm{hr}, 8 \mathrm{hr}$, $16 \mathrm{hr}$, and $32 \mathrm{hr}$, the general shapes of size distribution do not change much, but they follow a trend of decreasing the main peaks to $76 \mu \mathrm{m}, 54 \mu \mathrm{m}, 34 \mu \mathrm{m}$, and $26 \mu \mathrm{m}$. In Figure 1(a), the weight loss also decreases to large extent in this period. This means the structures of ARFA become rigid, and digestion occurs by etching the outer layers of particles. Generally, there are two small peaks at $0.8 \mu \mathrm{m}$ and $2.3 \mu \mathrm{m}$ in different acid digestion ARFA, which may be ascribed to acid-resistant building pieces of ARFA. The building pieces occur in very small amounts in raw ARFA and accumulate rapidly as ARFA is disintegrated in acid digestion process.

In Figure 7(b), the size distributions for base digestion ARFA and raw ARFA have been plotted for comparison. Even with step Base Dissolution I, the main peak has moved from $96 \mu \mathrm{m}$ in raw ARFA to $48 \mu \mathrm{m}$. At the same time, the two small peaks at $0.8 \mu \mathrm{m}$ and $2.3 \mu \mathrm{m}$ grow considerably. But with step Acid Dissolution, the position of main peak decreases only slightly to $42 \mu \mathrm{m}$, and the two small peaks display some shrinkage instead of expansion, which means some building pieces could have been digested by step Acid Dissolution. With step Base Dissolution II, the position of main peak shifts further slightly to $38 \mu \mathrm{m}$, and the two small peaks grow greatly, which probably means the production of enormous building pieces.

Acid and base digestions are very different in the mechanisms, side reactions, and products. Besides, acid digestion was carried out under mild conditions, and base digestion was performed at high temperatures and with high $\mathrm{NaOH}$ concentrations. As a result, the size distributions cannot be reproduced. Nevertheless, the building pieces of ARFA have been consistently identified by two digestion methods.

3.2.5. SEM-EDX. In many SEM pictures for disintegrated ARFA from acid and base digestions, acicular crystals have been frequently observed to have diameters of less than 


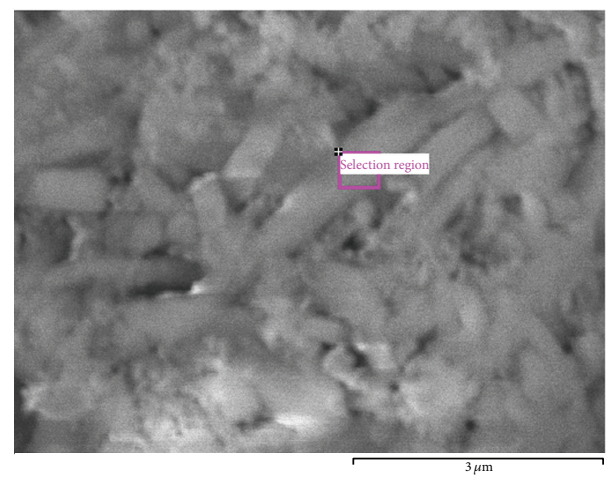

FIGURE 8: The SEM picture of building pieces in disintegrated ARFA. The region in the square has been selected for EDX elemental analysis (Al/Si molar ratio of 3.44).

one micrometer and lengths of a few micrometers. Similar observations have also been made in many previous SEM pictures $[5,19,25]$, despite the investigations made by different researchers and fly ashes taken from a variety of power plants.

Acicular forms have been previously regarded as the main characteristics of mullite, although irregular forms called chunky habit also occur in synthetic mullite [18]. In the SEM picture for ARFA in Figure 8, it is apparent that acicular crystals scatter in the disintegrated mass, with diameters of less than one micrometer and lengths of a few micrometers. Since size distributions have been measured by laser beams with the ARFA dispersed in water, the directions of acicular crystals may be at work, that is, the two peaks at $0.8 \mu \mathrm{m}$ and $2.3 \mu \mathrm{m}$ could actually reflect the average diameter and length of acicular crystals in disintegrated ARFA. In the selection region of SEM picture in Figure 8, an EDX analysis has been made to produce an Al/Si molar ratio of 3.44, which is in the neighborhood of 3 for ideal Al/Si molar ratio of mullite [18].

3.3. Dissolved Components and Glasses Compositions in Acid and Base Digestion Processes. Similar to the $\mathrm{K}_{2} \mathrm{O}$ calculations in Section 3.2.1, the weight percentages of acid and base digestion ARFA in Figure 1 and the weight percentages of components in acid and base digestion ARFA in Figure 2 can be used to calculate the absolute weights of components in ARFA from acid and base digestion processes, and the dissolved components can be obtained by subtracting the components in acid and base digestion ARFA from those in the raw ARFA. In Figure 9, components are given in percentages of the total weight of dissolved components as a function of digestion time. Dissolved components come from glasses as well as other phases, and with the identification of glasses in ARFA in Section 3.2, the glass compositions can be obtained.

3.3.1. Dissolved Components and Glasses Compositions in Acid Digestion Process. In Figure 9(a) for dissolved components of ARFA in acid digestion process, from the beginning to the interval of $2 \mathrm{hr}$, the dissolved components tend to increase in $\mathrm{SiO}_{2}$ and decrease in $\mathrm{Al}_{2} \mathrm{O}_{3}$. According to Figure 7(a), medium size particles of ARFA would be digested in the intervals up to $1 \mathrm{hr}$. According to Figure 5, ferrite spinel will be digested even in the interval of $15 \mathrm{~min}$. According to Figure 9(a), $\mathrm{CaO}, \mathrm{TiO}_{2}$, and $\mathrm{Fe}_{2} \mathrm{O}_{3}$ are also at the highest level in the beginning. These observations may mean ferrite spinel preferably occurs in medium size particles of ARFA, which could be partially composed of $\mathrm{CaO}$ and $\mathrm{TiO}_{2}$ besides $\mathrm{Fe}_{2} \mathrm{O}_{3}$ $[20,21]$.

At the intervals of $2 \mathrm{hr}$ and $4 \mathrm{hr}$ in Figure 9 (a), $\mathrm{SiO}_{2}$ and $\mathrm{Al}_{2} \mathrm{O}_{3}$ reach the highest and lowest levels and tend to decrease and increase in the extended periods of acid digestion time. According to the $\mathrm{K}_{2} \mathrm{O}$ standard with $7.1 \mathrm{hr}$ as the time for complete glass digestion in ARFA, the glasses by acid digestion process would have the following compositions: $\mathrm{SiO}_{2} 62.8 \mathrm{wt} \%, \mathrm{Al}_{2} \mathrm{O}_{3} 22.9 \mathrm{wt} \%, \mathrm{CaO} 5.1 \mathrm{wt} \%, \mathrm{TiO}_{2} 2.9 \mathrm{wt} \%$, $\mathrm{Fe}_{2} \mathrm{O}_{3} 2.3 \mathrm{wt} \%$, and $\mathrm{K}_{2} \mathrm{O} 1.0 \mathrm{wt} \%$. According to Figure 9(a), $\mathrm{K}_{2} \mathrm{O}$ retains $1.0 \pm 0.1 \mathrm{wt} \%$ till the interval of $8 \mathrm{hr}$, after which it slowly decreases to $0.8 \mathrm{wt} \%$ and $0.7 \mathrm{wt} \%$ with more components of ARFA being dissolved. Therefore, it can be said that "potassium appears to be reasonably well distributed throughout the glass" [19].

In Figure 9(a), it is also interesting to note that $\mathrm{TiO}_{2}$ seem to be in parallel with $\mathrm{Fe}_{2} \mathrm{O}_{3}$ in a wide range, with $\mathrm{TiO}_{2}$ slightly higher than $\mathrm{Fe}_{2} \mathrm{O}_{3}$. This means the two components could have the same origin. Among the possible minerals with the approximate ratios of $\mathrm{TiO}_{2}$ to $\mathrm{Fe}_{2} \mathrm{O}_{3}$, ilmenite seems to be the most likely. However, in the XRD spectra for raw ARFA in Figure 4, no peaks could be clearly assigned to ilmenite. If ilmenite does occur in alumina rich coal (ARC), the combustion processes involving reduction and oxidation could have destroyed parts of the mineral for the formation of ferrite spinel [26-28].

\subsubsection{Dissolved Components and Glasses Compositions in Base} Digestion Process. In Figure 9(b) for dissolved components of ARFA in base digestion process, higher $\mathrm{SiO}_{2}$ and lower $\mathrm{Al}_{2} \mathrm{O}_{3}$ are observed in step Base Dissolution I relative to the beginning of acid digestion process. There is also a higher $\mathrm{K}_{2} \mathrm{O}$ of $2.0 \mathrm{wt} \%$ in this step due to the similarity dissolution principle. With step Acid Dissolution, hydroxysodalite covering ARFA is destroyed by $\mathrm{HCl}$ to release $\mathrm{Al}_{2} \mathrm{O}_{3}$ as $\mathrm{AlCl}_{3}$ into solutions, and $\mathrm{CaO}, \mathrm{TiO}_{2}$, and $\mathrm{Fe}_{2} \mathrm{O}_{3}$ are also readily dissolved. In step Base Dissolution II, as more $\mathrm{SiO}_{2}$ is dissolved, other components decrease relatively in the dissolved components of ARFA. The glasses by base digestion method would have the following compositions: $\mathrm{SiO}_{2} 61.5 \mathrm{wt} \%, \mathrm{Al}_{2} \mathrm{O}_{3} 21.5 \mathrm{wt} \%, \mathrm{CaO} 9.1 \mathrm{wt} \%, \mathrm{TiO}_{2} 2.2 \mathrm{wt} \%$, $\mathrm{Fe}_{2} \mathrm{O}_{3} 2.2 \mathrm{wt} \%$, and $\mathrm{K}_{2} \mathrm{O} 1.1 \mathrm{wt} \%$.

As discussed above, the glass compositions by base digestions are very similar to those by acid digestions, usually with 0.1-1.4 wt\% difference for each component. One noticeable difference is a higher $\mathrm{CaO}$ in the glasses by base digestions, due to more $\mathrm{CaO}$ dissolved in step Acid Dissolution. The roles of additives on silicate glass structures can be very complicated, $\mathrm{Na}^{+}, \mathrm{K}^{+} \mathrm{Ca}^{2+}$, and $\mathrm{Mg}^{2+}$ are networking modifiers, and $\mathrm{Al}^{3+}$ can be either networking former or modifier $[16,29,30]$. Mixed layer smectite-illite clays have been reported to form a large proportion of minerals in the coals for power plants 


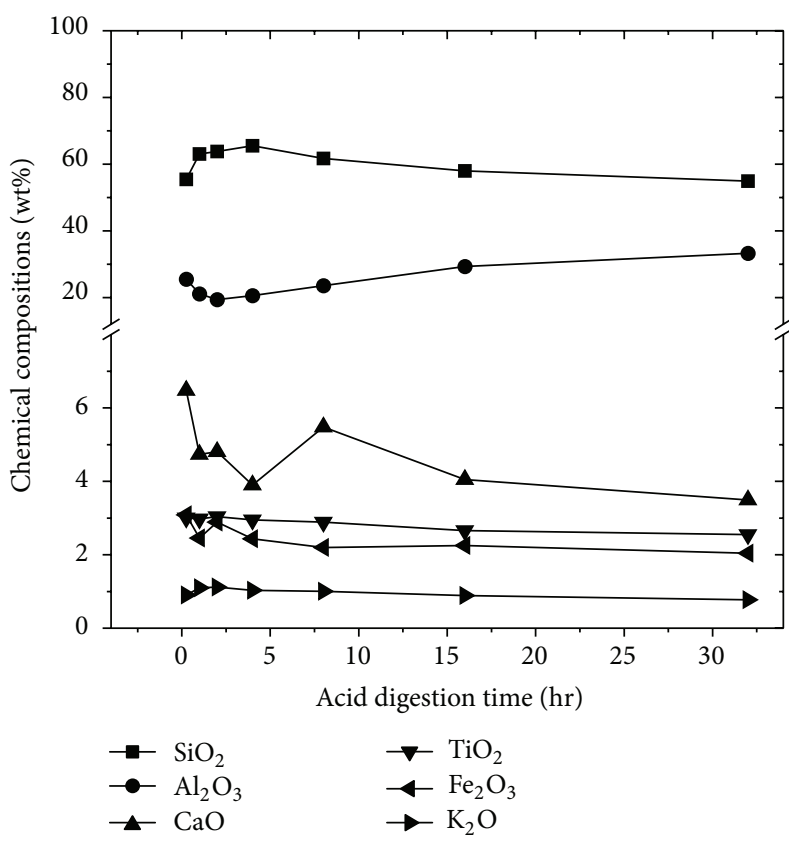

(a)

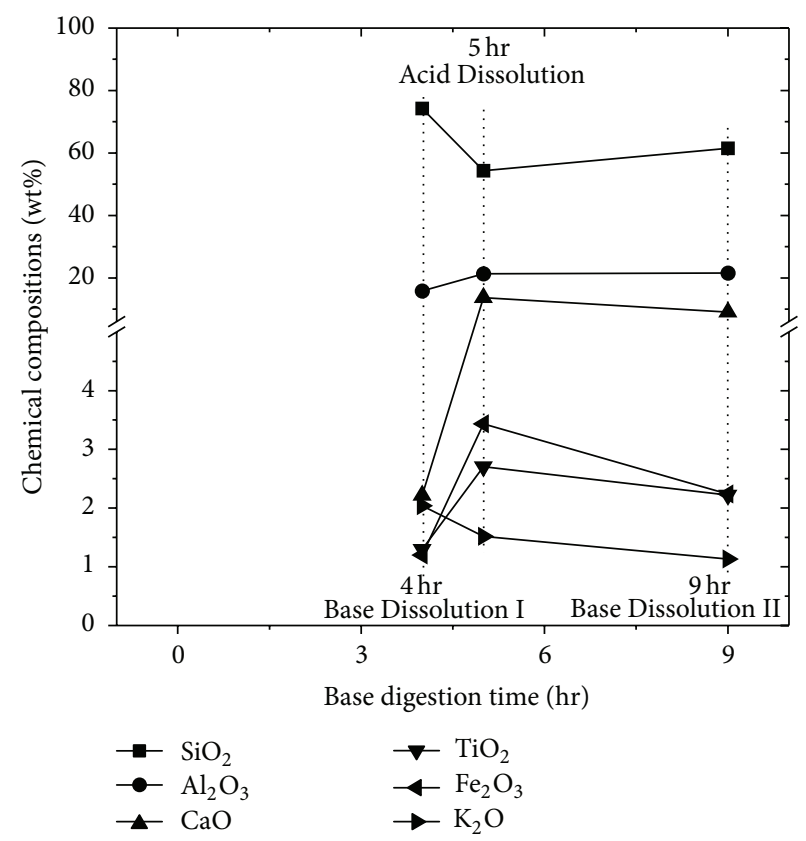

(b)

FIGURE 9: Chemical composition changes of dissolved components of ARFA in acid digestion process (a) as a function of time and base digestion process (b) as a function of step.

[16]. In particular, illite is by definition potassic, and "fixed" potassium occurs completely in the interlayers. It has been generally agreed that $\mathrm{K}_{2} \mathrm{O}$ or $\mathrm{Na}_{2} \mathrm{O}$ would bridge $\mathrm{SiO}_{2}$ and $\mathrm{Al}_{2} \mathrm{O}_{3}$ units in glasses. As more $\mathrm{K}_{2} \mathrm{O}$ or $\mathrm{Na}_{2} \mathrm{O}$ is added, more $\mathrm{Al}_{2} \mathrm{O}_{3}$ is taken up, and the glass content will increase in fly ashes $[16,29,30]$. According to Figures 3 and 9, over $95 \mathrm{wt} \%$ of $\mathrm{K}_{2} \mathrm{O}$ distributes evenly in glasses. Therefore, it is suggested that illite could have been transformed into the glasses to incorporate potassium, which allows for some explanation of the $\mathrm{K}_{2} \mathrm{O}$ standard.

3.3.3. Implications for Alumina Extraction from ARFA. According to the compositions and weights of glasses in Figures 1 and 9, for acid digestion process, there is $26.6 \mathrm{~g} \mathrm{SiO}_{2}$ in the digested glasses per $100 \mathrm{~g}$ ARFA, which should account for about $66.5 \mathrm{wt} \%$ of silica in ARFA. If the silica in glasses can be removed, then two thirds of $\mathrm{CaO}$ addition would be cancelled for alumina extraction from ARFA. However, with step Base Dissolution I in base digestion process, there is $13.8 \mathrm{~g} \mathrm{SiO}_{2}$ in the digested glasses per $100 \mathrm{~g}$ ARFA due to hydroxysodalite formation, which accounts for $34.5 \mathrm{wt} \%$ of silica in ARFA. Silica removal would be intensified in the predesilication process if hydroxysodalite formation can be checked. Such an idea has been partially realized in one recent paper, in which zeolite $\mathrm{P}$ was used to block the formation of hydroxysodalite, and a higher desilication rate has been achieved [12]. According to particle transformation in Figure 7(a) in acid digestion process, small particles are mostly disintegrated building pieces of ARFA, large particles would be etched in long time, and medium size particles are enriched in glasses and tend to be digested very rapidly. Therefore, if medium size particles could be screened out prior to alumina extraction, the left ARFA would have less glasses and accordingly less $\mathrm{SiO}_{2}$, resulting in a similar effect as predesilication.

\section{Conclusions}

The alumina rich fly ash (ARFA) with about $50 \mathrm{wt} \%$ alumina has been regarded as a real gift for China short of bauxite and brings about the hope for a self-contained alumina industry. For the many processes under development for alumina extraction from ARFA, silica should be reduced by predesilication to avoid the addition of enormous amounts of lime. Therefore, it is necessary to study the glasses in ARFA, which could be useful for the development and optimization of predesilication process.

In this work, chemical digestion methods were used to characterize the glasses in ARFA. The chemical compositions of acid and base digestion ARFA were measured by XRF. The $\mathrm{K}_{2} \mathrm{O}$ standard was used for the process depiction of acid digestion and the estimation of glass amount in ARFA. The weight of glasses by acid digestion was $2.7 \%$ more than that by base digestion, and the formation of hydroxysodalite blocked the glass digestion. The FTIR and XRD spectroscopies provided the evidences for phase transformation, and the size analysis and SEM-EDX yielded rich information on particle transformations and identifications in acid and base digestion processes. Medium size particles were found to hold most of glasses in ARFA. The compositions for the digested components of ARFA in acid and base dissolutions were calculated, and the glass compositions were accordingly defined. The glass formation by illite could be the foundation for the $\mathrm{K}_{2} \mathrm{O}$ standard for glass digestion in fly ashes. $\mathrm{TiO}_{2}$ and 
$\mathrm{Fe}_{2} \mathrm{O}_{3}$ in ARFA were found to be correlated and could have their origin from ilmenite. With these findings, this work has provided new knowledge on the glasses in fly ashes and suggested the ways to improve the predesilication process for alumina extraction from ARFA.

\section{Conflict of Interests}

The authors declare that there is no conflict of interests regarding the publication of this paper.

\section{Acknowledgments}

This work was financially supported by the National Hi-Tech Research and Development Program of China (863 Program, MOST 2012AA06A115), the National Natural Science Foundation of China (NSFC, 51208367), and the China Shenhua Group Science and Technology Innovation Foundation project (ST930013SH05).

\section{References}

[1] Z. T. Yao, M. S. Xia, P. K. Sarker, and T. Chen, "A review of the alumina recovery from coal fly ash, with a focus in China," Fuel, vol. 120, pp. 74-85, 2014.

[2] Z. Zhang, Research on extraction of alumina and other useful resources from high aluminium fly ash [Ph.D. Dissertation], Northwest University, Xian, China, 2007.

[3] L. Zhao, Q. Sun, B. Wang et al., "Ultra-clear glass production from fly ash," in Proceedings of the 29th International Conference on Solid Waste Technology and Management, pp. 276-280, Philadelphia, Pa, USA, March-April 2014.

[4] L. Zhao, Q. Sun, B. Wang et al., "Alumina extraction from fly ash by the MgO sintering method: waste reduction and utilization," in Proceedings of the Nanotech 2014: Technical Proceedings of the 2014 NSTI Nanotechnology Conference \& Expo, pp. 226-229, Washington, DC, USA, June 2014.

[5] R. T. Hemmings and E. E. Berry, "On the glass in coal fly ashes: recent advances," Materials Research Society Symposium Proceedings, vol. 113, pp. 3-38, 1988.

[6] C. Zevenbergen, J. P. Bradley, L. P. van Reeuwijk, A. K. Shyam, O. Hjelmar, and R. N. J. Comans, "Clay formation and metal fixation during weathering of coal fly ash," Environmental Science and Technology, vol. 33, no. 19, pp. 3405-3409, 1999.

[7] H. Chen, A. Laskin, J. Baltrusaitis, C. A. Gorski, M. M. Scherer, and V. H. Grassian, "Coal fly ash as a source of iron in atmospheric dust," Environmental Science and Technology, vol. 46, no. 4, pp. 2112-2120, 2012.

[8] X. Querol, N. Moreno, J. C. Umaña et al., "Synthesis of zeolites from coal fly ash: an overview," International Journal of Coal Geology, vol. 50, no. 1-4, pp. 413-423, 2002.

[9] P. Kumar, N. Mal, Y. Oumi, K. Yamana, and T. Sano, "Mesoporous materials prepared using coal fly ash as the silicon and aluminium source," Journal of Materials Chemistry, vol. 11, no. 12, pp. 3285-3290, 2001.

[10] M. Inada, Y. Eguchi, N. Enomoto, and J. Hojo, "Synthesis of zeolite from coal fly ashes with different silica-alumina composition," Fuel, vol. 84, no. 2-3, pp. 299-304, 2005.
[11] D. Mainganye, T. V. Ojumu, and L. Petrik, "Synthesis of zeolites Na-P1 from South African coal fly ash: effect of impeller design and agitation," Materials, vol. 6, no. 5, pp. 2704-2089, 2013.

[12] G. Zhu, W. Tan, J. Sun et al., "Effects and mechanism research of the desilication pretreatment for high-aluminum fly ash," Energy and Fuels, vol. 27, no. 11, pp. 6948-6954, 2013.

[13] C. R. Ward and D. French, "Determination of glass content and estimation of glass composition in fly ash using quantitative $\mathrm{X}$ ray diffractometry," Fuel, vol. 85, no. 16, pp. 2268-2277, 2006.

[14] O. Font, N. Moreno, X. Querol et al., "X-ray powder diffractionbased method for the determination of the glass content and mineralogy of coal (co)-combustion fly ashes," Fuel, vol. 89, no. 10, pp. 2971-2976, 2010.

[15] M. Van Roode, E. Douglas, and R. T. Hemmings, "X-ray diffraction measurement of glass content in fly and slags," Cement and Concrete Research, vol. 17, no. 2, pp. 183-197, 1987.

[16] J. H. Brindle and M. J. McCarthy, "Chemical constraints on fly ash glass compositions," Energy and Fuels, vol. 20, no. 6, pp. 2580-2585, 2006.

[17] L. D. Hulett Jr., A. J. Weinberger, K. J. Northcutt, and M. Ferguson, "Chemical species in fly ash from coal-burning power plants," Science, vol. 210, no. 4476, pp. 1356-1358, 1980.

[18] L. D. Hulett and A. J. Weinberger, "Some etching studies of the microstructure and composition of large aluminosilicate particles in fly ash from coal burning power plants," Environmental Science and Technology, vol. 14, no. 8, pp. 965-970, 1980.

[19] C. I. Kilgour and S. Diamond, "The internal structure of a lowcalcium fly ash," MRS Proceedings, vol. 113, pp. 65-74, 1987.

[20] D. S. Mathew and R.-S. Juang, "An overview of the structure and magnetism of spinel ferrite nanoparticles and their synthesis in microemulsions," Chemical Engineering Journal, vol. 129, no. 13, pp. 51-65, 2007.

[21] V. V. Zyryanov, S. A. Petrov, and A. A. Matvienko, "Characterization of spinel and magnetospheres of coal fly ashes collected in power plants in the former USSR," Fuel, vol. 90, no. 2, pp. 486-492, 2011.

[22] C. Rüssel, "Nanocrystallization of $\mathrm{CaF}_{2}$ from $\mathrm{Na}_{2} \mathrm{O} / \mathrm{K}_{2} \mathrm{O} / \mathrm{CaO} /$ $\mathrm{CaF}_{2} / \mathrm{Al}_{2} \mathrm{O}_{3} / \mathrm{SiO}_{2}$ glasses," Chemistry of Materials, vol. 17, no. 23, pp. 5843-5847, 2005.

[23] D. Voll, P. Angerer, A. Beran, and H. Schneider, "A new assignment of IR vibrational modes in mullite," Vibrational Spectroscopy, vol. 30, no. 2, pp. 237-243, 2002.

[24] T. Henmi, "Synthesis of hydroxy-sodalite ('zeolite') from waste coal ash," Soil Science and Plant Nutrition, vol. 33, no. 3, pp. 517$521,1987$.

[25] S. Diamond, "Particle morphologies in fly ash," Cement and Concrete Research, vol. 16, no. 4, pp. 569-579, 1986.

[26] Y.-M. Wang, Z.-F. Yuan, Z.-C. Guo, Q.-Q. Tan, Z.-Y. Li, and W.-Z. Jiang, "Reduction mechanism of natural ilmenite with graphite," Transactions of Nonferrous Metals Society of China, vol. 18, no. 4, pp. 962-968, 2008.

[27] M. A. R. Dewan, G. Zhang, and O. Ostrovski, "Phase development in carbothermal reduction of ilmenite concentrates and synthetic rutile," ISIJ International, vol. 50, no. 5, pp. 647-653, 2010.

[28] W. Xiao, X.-G. Lu, X.-L. Zou, X.-M. Wei, and W.-Z. Ding, "Phase transitions, micro-morphology and its oxidation mechanism in oxidation of ilmenite $\left(\mathrm{FeTiO}_{3}\right)$ powder," Transactions of Nonferrous Metals Society of China (English Edition), vol. 23, no. 8, pp. 2439-2445, 2013. 
[29] B. Hehlen and D. R. Neuville, "Raman response of network modifier cations in alumino-silicate glasses," The Journal of Physical Chemistry B, vol. 119, no. 10, pp. 4093-4098, 2015.

[30] A. Bernasconi, M. Dapiaggi, A. Pavese, D. T. Bowron, and $\mathrm{S}$. Imberti, "Local structure of Si-Al-Ca-Na-O glasses from coupled neutron and X-ray total scattering data," Journal of Physical Chemistry B, vol. 116, no. 43, pp. 13114-13123, 2012. 

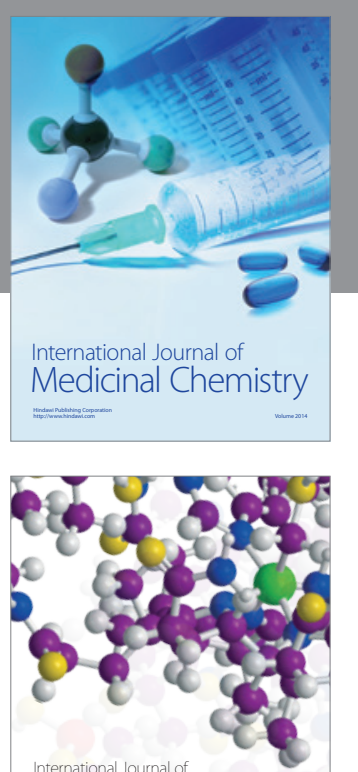

Carbohydrate Chemistry

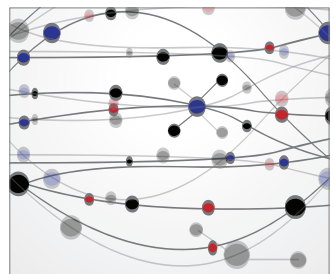

The Scientific World Journal
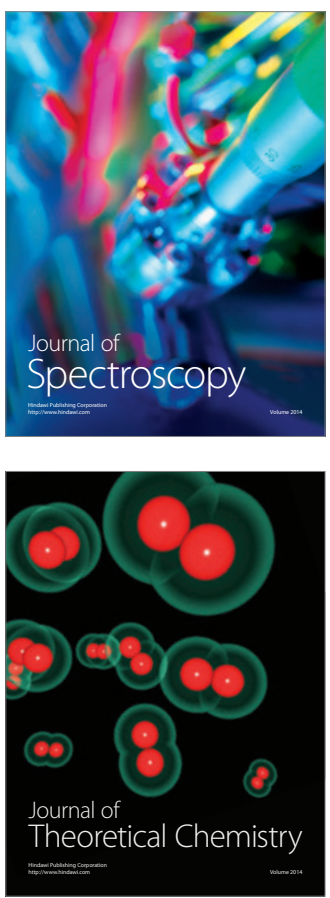
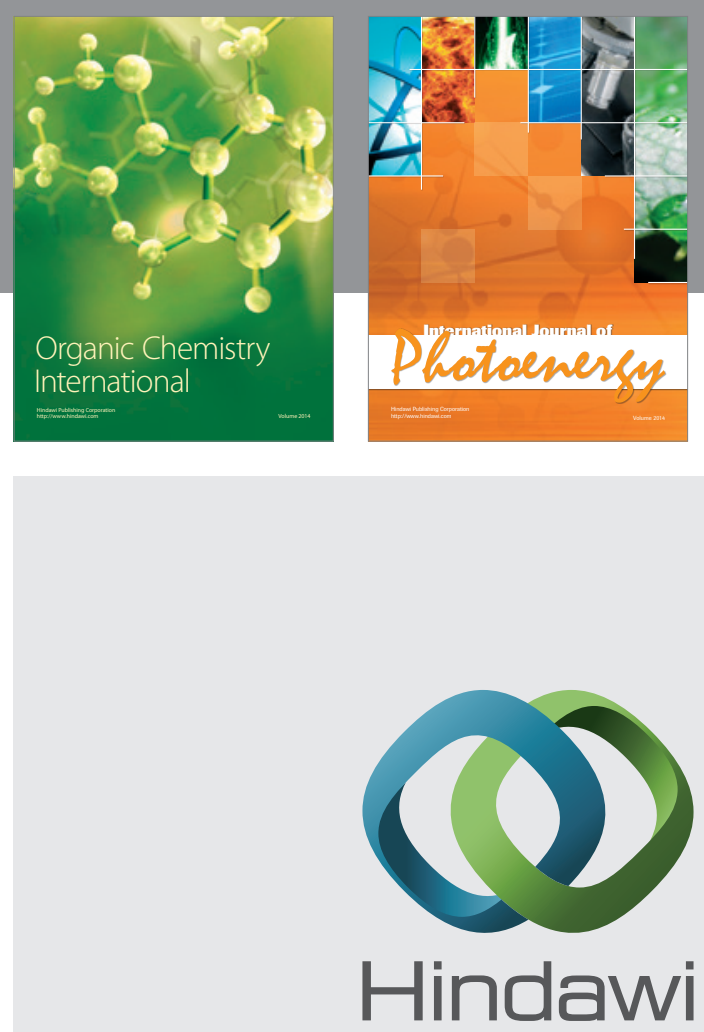

Submit your manuscripts at

http://www.hindawi.com

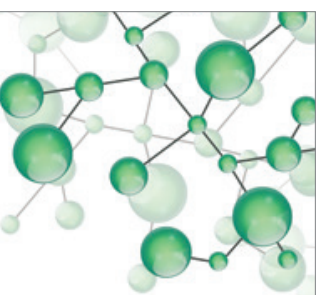

International Journal of

Inorganic Chemistry

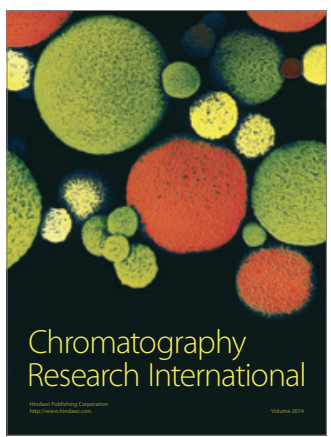

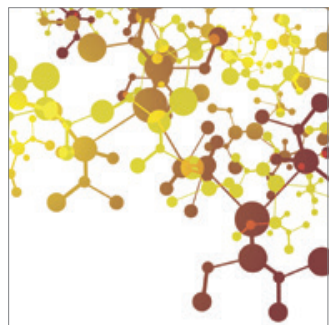

Applied Chemistry
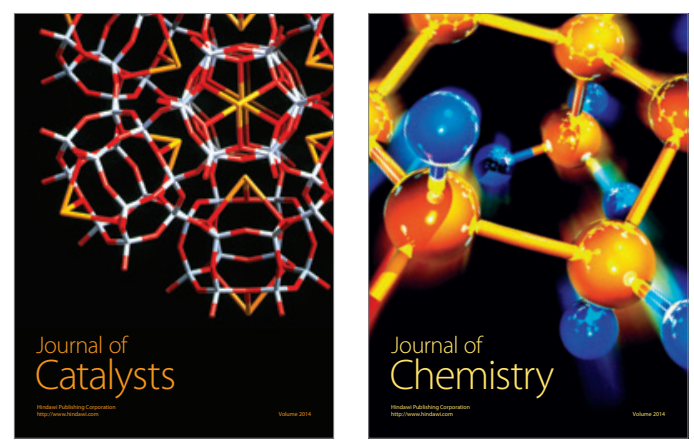
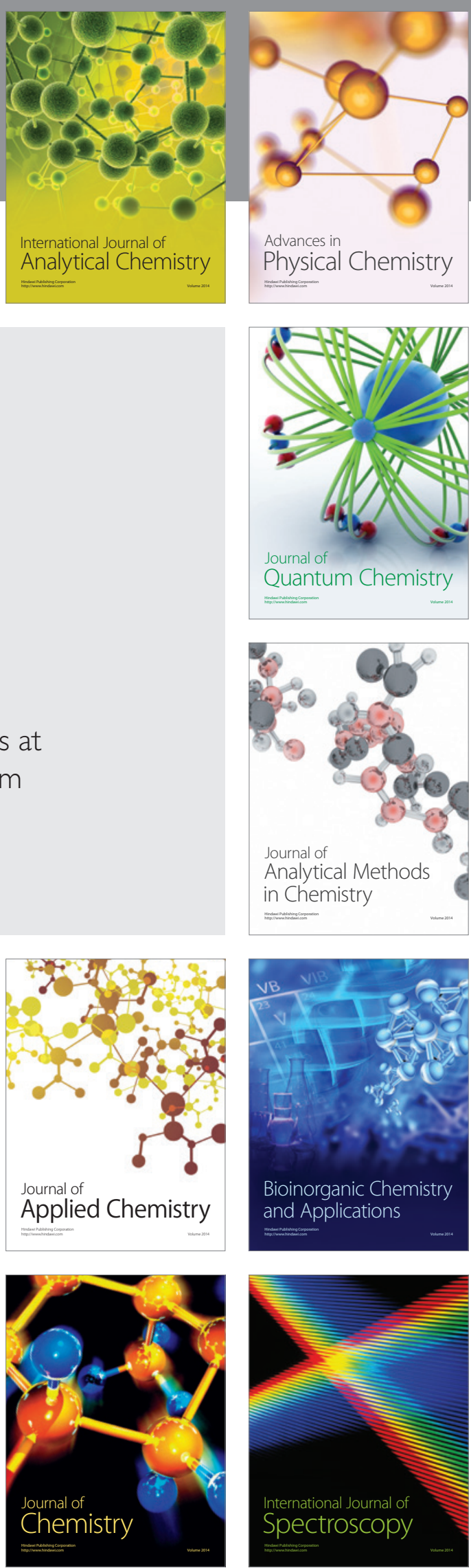